\title{
«ESCRIBIR UN DIARIO Y UNA HORA DE BAÑO»: VIDAS PRIVADAS EN LA CORTE DE MADRID (1650-1680) ${ }^{1}$
}

\author{
LAURA OLIVÁN \\ Universidad de Granada
}

Fecha de recepción: enero 2012

Fecha de aceptación: febrero 2012

En memoria de Carlos Gómez-Centurión. Dedicado a Pilar.

\section{SOBRE TRAJES Y RECETARIOS}

El 27 de abril de 1674, Fernando de Harrach, embajador del Imperio en Madrid, salió a la plaza de la Cebada para despedir a su predecesor en el cargo: el conde de Pötting que, junto con su esposa y tras largas fatigas cortesanas, se disponía a retornar a la Viena imperial. Dada su predisposición a fijar en su memoria los datos referentes a la representación del cuerpo, el conde de Harrach registró en su diario la descripción de la indumentaria que el matrimonio portaba ${ }^{2}$. Enfundados en el vestido estilado en la corte de Madrid, los condes de Pötting cerraron su ciclo diplomático en la Villa. Probablemente, el profundo conocimiento que tanto Pötting como Harrach, en calidad de embajadores, tenían de la cultura de las apariencias ${ }^{3}$, les había llevado aquel día de primavera de 1674 a jugar con la indumentaria y registrar los obligados códigos de vestimenta que en el siglo que corre sólo tendrían condición de meros detalles.

Golillas y mantillas no fueron los únicos «recuerdos» que Eusebio Pötting y su esposa se llevaron de la corte de Madrid. En sus bien pertrechadas carrozas se acomodaba la gran biblioteca del marqués de Cábrega ${ }^{4}$. Todos los ejemplares, más de 2400 ,

1. Artículo realizado dentro del proyecto del Ministerio HAR2011-26435-C03-03.

2. ÖStA. AVA-FA(Österreichisches Staatsarchiv-Allgemeines Verwaltungsarchiv, Familienarchiv). Harrach. Hs. 6, vol I, p. 174-174v. Junto a Bianca Lindorfer estoy preparando la edición de este diario.

3. RocHe, Daniel: La culture des apparences, París, 1989.

4. Nieto Nuño, Miguel: Fondos Hispánicos de la Biblioteca Nacional de Viena, Madrid, 1989. 
estaban destinados al emperador Leopoldo I, lo que no sería óbice para que Pötting deslizara su mirada por alguna de las preciadas obras como El regalo de la vida huma$n a^{5}$.

La creciente preocupación de las elites nobiliarias de la edad moderna por las vestimentas, la preservación de la salud y la higiene corporal, indispensables en la representación y ostentación cortesanas, nos permite aventurar el posible hojeo de las páginas de El Regalo por parte de Pötting. La obra de Juan Vallés podría incluirse en el género de los libros de secretos impresos que tanto éxito tuvieron en los ambientes más selectos de la Europa de los siglos XVI y XVII ${ }^{6}$. Estos recetarios impresos articulados cual compendios de magistrales fórmulas reparadoras del cuerpo y alma, alcanzaron una popularidad y valor semejante a los manuales de comportamiento y civilidad que habían venido educando desde el siglo XVI a la cada vez más sofisticada nobleza europea $^{7}$. Ampliamente difundidos de manera impresa, los secretos en torno al cuidado del cuerpo también aparecieron de manera manuscrita en recetarios celosamente conservados por familias nobiliarias ampliamente versadas en la vida de Corte ${ }^{8}$.

No obstante, a pesar de haber sido analizados y escudriñados por aficionados e historiadores, los libros de secretos y recetarios siguen siendo lo que su mismo nombre indica: secretos. Claros son sus usos terapéuticos basados en la medicina galénica imperante en el periodo e igualmente diáfanos se presentan los objetivos de las recetas: embellecer y cultivar un cuerpo virtuoso para lucirlo en la exigente sociedad cortesana; sin embargo, parecen esconder unos usos y disfrutes privados de los que poco se conoce. Los «secretos» podrían haber estado no sólo al servicio de la apariencia, sino también al de los cuerpos nobles que quisieron huir de la tiranía de ésta. Primero como recurso y luego por placer, estas recetas proporcionarían íntimos consuelos a sus propincuos dueños, como el conde de Harrach, espectador de la marcha de Pötting y que a fecha de ese día de abril de 1674, ya tenía en su poder un recetario manuscrito del siglo XVI, que posiblemente había pertenecido a una partera o nodriza de doña Juana Álvarez de Toledo, marquesa de Villena9.

Tras estas digresiones en torno a los recetarios y el deleite vedado a las miradas indiscretas, debo concretar los objetivos de este artículo y justificar esta prolija introducción iniciada con una referencia al traje y otra a los libros de secretos. El haberme detenido en estos curiosos textos tiene su sentido: esta fuente para leer en silencio, contenedora de recetas que se debían elaborar en privado y cuyos resultados acaso no tenían más fin que solazar espíritus nobles, será el amuleto-guía a la hora de analizar formas de privacidad entre los nobles de la corte madrileña del siglo XVII. Trataré de

5. Serrano Larráyoz, Fernando (ed): El Regalo de la Vida Humana, Pamplona, 2008.

6. EAMON, William: Science and the secrets of Nature. Book of secrets in Medieval and Early Modern culture, Princenton, 1996.

7. Ibidem. pp. 3-4.

8. PÉREZ SAMPER, María de los Ángeles: «Recetario de mujeres y para mujeres», Cuadernos de Historia Moderna, 19 (1997) pp. 121-154.

9. ÖStA. AVA-FA. Harrach, Hs 482. 
presentar someramente algunos rasgos de la vida privada del conde de Harrach y de otros nobles de la corte de Madrid que, bien a través de estos recetarios, bien a través de una sociabilidad «pequeña», mantuvieron una relación con el cultivado diplomático.

Este apasionante recorrido nos conducirá de la corte a la aldea, del recurso al solaz y del embajador cortesano al cortesano discreto.

\section{EN LA ALDEA: LO ÍNTIMO Y LO PRIVADO EN LA CORTE BARROCA.}

Público, privado, intimidad, secreto... son categorías que a lo largo de los siglos han adquirido significados diversos. Las distintas acepciones que estas palabras han recabado a lo largo del tiempo y las que tienen en la actualidad, fruto de los cambios sociales experimentados en los siglos XVIII y XIX, las convierten en piezas difíciles de encajar en los contextos históricos de la edad moderna. Estos obstáculos iniciales no fueron insalvables para los historiadores de Annales Georges Duby y Philippe Ariès que, en los años ochenta y guiados por la estela dejada por filósofos como Habermas ${ }^{10}$ y sociólogos del calibre de Norbert Elias ${ }^{11}$, acometieron con gran éxito la realización de una historia de la vida privada.

En España, la atracción por los procesos de construcción de lo público y lo privado ha ido in crescendo y prueba de ello son las aportaciones que se han hecho desde la historia de las mujeres. A finales de los noventa, Isabel Morant y Mónica Bolufer dedicaron a estos temas un monográfico en la revista Studia Histórica. En la introducción, estas autoras no dejaron de señalar como una de las principales carencias de las magnas empresas de Habermas, Elias, Duby y Ariès, el escaso énfasis depositado en la perspectiva de género a la hora de abordar un proceso crucial en la historia cultural de Occidente $^{12}$. La sonada ausencia de esta categoría sorprendió a Morant en tanto en cuanto las distintas construcciones socio-culturales de lo masculino y lo femenino, el concepto hombre y el concepto mujer, así como las intensas y controvertidas relaciones establecidas entre los mismos en el Antiguo Régimen, se vislumbran como parámetros fundamentales en la configuración de privacidades y sociabilidades nuevas del mundo occidental. Morant también indicó que la tradicional asociación de lo femenino con la esfera moral en el siglo XVIII se presentaba como una de las claves del avance de lo privado en las sociedades contemporáneas ${ }^{13}$. Siguiendo este nexo entre feminidad y nuevas formas de privacidad, Benedetta Craveri rindió su particular homenaje a la mujer como precursora de la sociabilidad mundana en su amena y «narrativa» obra La cultura de la conversación ${ }^{14}$. Evocando aquel «estilo medio» de la época, el punto

10. HABERMAS, Jürgen: Historia y crítica de la opinión pública. Barcelona, 1981.

11. ELIAS, Norbert: Über den Prozeß der Zivilisation. Soziogenetische und psychogenetische Untersuchungen. Basilea, 1939.

12. Morant, Isabel y BolufER, Mónica: «Historia de las mujeres e historia de la vida privada: confluencias historiográficas», Studia Histórica. Historia Moderna, 19 (1998), pp. 17-23.

13. Ibidem. p. 21.

14. CRAVERI, Benedetta: La cultura de la conversación, Madrid, 2007. 
de originalidad aportado por Craveri consiste en haber investido de la aureola fundacional del arte de la conversación a las mujeres nobles francesas, y no a las del siglo XVIII como cabría esperar, sino a las del siglo XVII, siendo madame de Rambouillet la primera que, harta de las brutales maneras de Enrique IV, habría decidido refugiarse en su hotel de la rue Saint-Thomas-du-Louvre para disfrutar de reducidas veladas de sociabilidad refinada y vivir así la delicadeza del mundo-ruelle ${ }^{15}$.

Unir culturalmente los siglos XVII y XVIII y volver la mirada a la corte para encontrar cortesanos -en este caso cortesanas- propulsoras de novedosas formas de sociabilidad mundana además de nuevos espacios de privacidad ${ }^{16}$ supone una apuesta no demasiado arriesgada pero sí valiente y sumamente sugerente. La Historia de la vida privada de Ariès no eludió el tema, pues uno de sus capítulos redactado por Revel recoge estas inquietudes de privacidad en las sociedades cortesanas a través del análisis de una civilidad que se reveló esencial en la construcción de la individualidad ${ }^{17}$. Aunque la aportación de Revel fue sin duda brillante, su focalización casi en exclusiva en Francia y su escasa profundización en la adopción de practicas privadas entre la alta nobleza cortesana del XVII instiga al investigador a seguir los caminos de lo privado trazados en el mundo áulico. En este sentido resultan muy inspiradores los estudios de Roger Chartier, y en la historiografía española las publicaciones de Fernando Bouza ${ }^{18}$ y Santiago Martínez ${ }^{19}$. Los análisis que estos historiadores han realizado sobre la cultura cortesana y el habitus nobiliario de la nobleza han sido fundamentales para perfilar no sólo escrituras privadas, sino también «vidas privadas».

Pero pasemos a reflexionar sobre las categorías de privado, íntimo o secreto. En su introducción a su Historia de la vida privada, Philippe Ariés, sentenció que en la edad modera «la cámara [lo público] y el tesoro [lo privado] se confunden» ${ }^{20}$. Ya hemos alertado antes del peligro que supone el manejo de categorías contemporáneas para el análisis de tiempos pasados con dispares códigos culturales. Por precaución, parece obligado acometer una deliberación previa. Una solución eficaz aunque no totalmente satisfactoria puede ser el recurrir a las definiciones que aparecen en El Tesoro de la Lengua castellana de Covarrubias de 1616 y en el Diccionario de Autoridades en una de sus ediciones del siglo XVIII (1738). La franja temporal elegida resulta clave para el abordaje de esta compleja temática pues en esa centuria parece operarse un cambio considerable en la concepción de lo privado. En el Tesoro, «privado» se define de la

\section{Ibidem, p. 24.}

16. Ibidem, pp. 14-15.

17. ReVel, Jaques: «Los usos de la civilidad», ARIÈs, Philippe y DubY, Georges, op, cit. pp. 169-209. Para una reflexión sobre la identidad: BOLUfER, Mónica: «Identidad individual y vínculos sociales en el Antiguo Régimen», DAVIS, J.C, y BURDIEL, Isabel (eds.): El otro, el mismo. Valencia, 2005, pp. 131-140.

18. BouZA, Fernando: Imagen y propaganda. Capitulos de historia cultural del reinado de Felipe II. Madrid, 1998.

19. MARTíNEZ HERNÁNDEZ, Santiago: «Memoria aristocrática y cultura letrada: usos de la escritura nobiliaria en la Corte de los Austrias», Cultura escrita y sociedad, 3 (2006), pp. 58-112.

20. ARIÈs, Philippe y DUBY, Georges: «Introducción», op, cit, p. 7. 
siguiente manera: «el que ha sido excluido de oficio, dignidad. Privación» ${ }^{21}$ e inmediatamente debajo aparece definido el verbo: «privar» con un significado «político» que parece contradecir la primera acepción: «privar, en otra significación, vale ser favorecido de algún señor de privatus.a.um. cosa propia y particular: porque se particulariza con el, y le diferencia de los demas: y este se llama Privado, y el favor que el señor le da Privança». En el primer cuarto del siglo XVII, la ambigüedad estaba servida: privado podía significar tanto favorecido como desfavorecido por la gracia regia. Un siglo después el equívoco desaparece, pues el Diccionario de Autoridades de 1738 aporta una acepción muy cercana a la actual: «significa también lo que se executa a vista de pocos, familiar y domésticamente, y sin finalidad ni ceremonia alguna, o lo que es particular y personal de cada uno».

Si tomamos la palabra «íntimo», se observa que a principios del siglo XVII este vocablo ya se asociaba con la amistad y el afecto: «lo muy propio y del alma, como íntimo amigo y querido del corazón $»^{22}$, sin embargo, la palabra intimidad aparece por primera vez en el Diccionario como «confianza amistosa o amistad estrecha de corazón» por ende, no termina de vincularse al cuerpo. Más relación con lo corporal parece tener el secreto en el Tesoro, pues además de aparecer definido como: «todo lo que está encubierto y callado. Lugar secreto, donde no concurre la gente, cosa secreta que se encomienda uno a otro» ${ }^{23}$ se presenta asociado a las funciones fisiológicas: las «secretas» eran «las letrinas, por estar en parte secreta o desviada». El secreto, además de aludir al silencio y lo oculto, se relacionaba íntimamente con el cuerpo; no debe por tanto sorprender que los libros de secretos recogieran fórmulas destinadas al cuidado de lo corporal. En el siglo XVII, el cuerpo y el secreto estaban «condenados a entenderse». En resumen: con ciertas salvedades, se podría afirmar que la transformación en la concepción de lo privado se detecta entre 1616 y 1738 y que este cambio, por las connotaciones «apolíticas» o políticas (y por tanto cortesanas) que recababa el término en el siglo de Oro, parece que debió operarse también -aunque no únicamente- en la corte y en el siglo XVII.

Por tanto cabría lanzar la siguiente hipótesis: «privado» de cargo, el gran noble desengañado se refugia en la «aldea», aquel lugar mítico y natural opuesto a la hipocresía palaciega y al infausto fasto que brilla en la Corte. Como afirma Bouza, los nobles habrían acudido a esta arcadia no por disposición propia sino por necesidad ${ }^{24}$. Aunque este estado indeseable se convertiría, con el tiempo y aún antes de lo esperado, en mundo de esparcimiento. Así, la aldea se prefigura no sólo como contrapunto a la Corte sino como reducto donde ciertas prácticas cortesanas adquirieron valores tan privados como placenteros. El conde de Harrach está en ese grupo de nobles que encontraron consuelo y prevención de melancolías en prácticas como la conversación o el baño.

21. Covarrubias, Sebastián: Tesoro de la Lengua Española, Madrid, 1611, 596v.

22. Ibidem. p. $506 \mathrm{v}$.

23. Ibidem. p. 24v.

24. BouZA, Fernando: op, cit. pp. 200-201. 


\subsection{Melancolía y cuidado del cuerpo: del baño del conde de Harrach a los perfumes del duque de Montalto}

«Sie haben in meinem zimer sich in ein grossen spiegel gesehen, welher ihnen wunderlich vorkumen, solhen angerührt undt miteinander ihr sprach geredt $»^{25}$.

El 31 de julio de 1674, la condesa de Harrach entró en la habitación de su marido con tres criadas moras de entre diez y once años. Allí, las tres niñas se encontraron con un objeto novedoso: un gran espejo al que no dudaron en acercarse. La contemplación del reflejo de su propia imagen les maravilló de tal manera que comenzaron a hablar entre ellas con gran alboroto y en su propia lengua, olvidando que estaban en presencia de sus señores.

Esta anécdota, además de resultar tremendamente sugestiva, concentra múltiples significaciones culturales: en primer lugar nos revela que Harrach tenía en su habitación un espejo de cuerpo entero, un «grossen spiegel». En tanto solitario habitante de la Zimmer más o menos privada de nuestro embajador, este espejo se configura simbólicamente cual metáfora del sujeto ${ }^{26}$. Así, la sorpresa experimentada por las tres pequeñas esclavas tiene profundas implicaciones sociales y culturales: el espejo devolvía a Harrach una imagen de su cuerpo entero que no le causaba extrañeza, al contrario, el reflejo de sí mismo le resultaba familiar porque estaba acostumbrado a un «yo» al que no estaban habituadas las tres niñas moras que eran completamente ajenas al universo cultural y social de una nobleza cortesana cada vez más consciente de su individualidad corporal. Sin duda, este episodio sirve para demostrar que Harrach era partícipe de las nuevas actitudes frente al cuerpo propio como el pudor o las prácticas de preservación de la salud alejadas de las miradas ajenas, tales como el baño.

Como ha demostrado Vigarello, la higiene en el siglo XVII se basaba en las apariencias: el lavado de manos y cara con agua, el abundante uso de perfumes y la identificación de la limpieza con la indumentaria de color blanco ${ }^{27}$. Sin embargo, el conde de Harrach se bañaba con cierta frecuencia en baños (probablemente de vapor $^{28}$ ) íntimos y prolongados, que realizaba normalmente a última hora del día. Como el vapor del agua caliente entraba por los poros y debilitaba el cuerpo, el descanso posterior era obligación.

Por una anotación en el diario, sabemos que disfrutaba de su baño lejos de las miradas de otros. La tarde del 30 de agosto de 1674 despachó a su visita porque quería bañarse: «Umb 7 uhr ist der Don Carlos Ridolfi zu mir komen, weillen ich aber baaden

25. ÖStA. AVA-FA. Hs. 6. vol I, pp. 217v-218. Traducción mía: «Han entrado en mi habitación y se han mirado en un gran espejo, esto les ha causado tal maravilla que han comenzado a hablar entre ellas en su propia lengua». Esta transcripción y las siguientes son de Lindorfer. ÖStA. AVA-FA. Hs. 6. vol I, pp. $217 \mathrm{v}-218$

26. Melchior-Bonnet, Sabine: The Mirror, A History. Londres, 2001, p. 3.

27. Vigarello, Georges: Le prope et le sale. París, 1985.

28. Baño de vapor: CARVAllo, Sandra: «Health, Beauty and higiene», DENNIS, Flora y AJMAR-WoLlHEIM. Marta (eds.), At Home in Renaissance Italy, Londres, 2008, p. 181. 
wollen, hat er nit lang aufgehalten ${ }^{29}$. Aunque cabe preguntarse si se bañaría solo o con el auxilio de algún criado, como estilaba -aunque con agua- la marquesa de Chatelet en 1746, cuyo valet acostumbraba a ser un elemento más de la doméstica escena de limpieza corporal ${ }^{30}$.

Resulta pertinente pensar en las razones que inclinaron a Harrach a adoptar una práctica que no gozaba de demasiado predicamento en la cultura de las apariencias, aunque sí en la órbita médica ${ }^{31}$. Su médico, el doctor Billote, recomendaba los baños de una hora que dependiendo de las dolencias podían llevarse a cabo diariamente ${ }^{32}$. El baño reconfortaba saludablemente el cuerpo pero no necesariamente lo preparaba para ser exhibido en sociedad, pues para triunfar higiénicamente en la Corte bastaba con cuidar la imagen. Los momentos elegidos indican que el principal motivo por el que Harrach tomaba un baño no era la mejora de su apariencia ya que no se bañaba antes de aparecer en palacio, ni siquiera después, aunque tarde o temprano debía presentarse en el Alcázar de Madrid. Los motivos de sus inmersiones o vaporizaciones eran la conservación de la salud, cuyo rito era privado.

Claro está que su baño era reservado o al menos no apto para las miradas no domésticas como la de Carlos Ridolfi, aquel visitante que tuvo que acortar su visita porque su anfitrión quería bañarse. Esta privacidad se configura como privilegio del cuerpo noble, cuyas características diferenciadas del resto de los cuerpos plebeyos lo hacen especialmente vulnerable a ciertas enfermedades ya no sólo físicas sino también «espirituales». La melancolía acechaba a los cuerpos de cortesanos, embajadores y favoritos que se desvivían por mantener su estatus. ¿Acaso el baño prevenía enfermedades del alma además de corporales? ¿Acaso su privacidad y singularidad vaporosa no se correspondían con el rango del cuerpo noble, más vulnerable a tristezas políticas? Parece que existe una profunda vinculación entre la lucha cortesana y el baño. Pero sigamos el rosario de abluciones o vaporizaciones privadas que el embajador cita en su diario, porque la cura espiritual, el agua y el vapor se entrelazan continuamente.

Casualmente, o no tanto, Harrach tomó uno de sus baños un día antes de la fiesta San Juan ${ }^{33}$ ¿Se preparó de este modo para el baño ritual que se estilaba aquella noche y del que tanto un pintor anónimo ${ }^{34}$ como el famoso Cassiano del Pozzo nos han dejado impagables testimonios? Del Pozzo relató en su diario de 1626 esta fantástica mezcla de cuerpos nobles y plebeyos en el Manzanares:

«[...] gran parte de la ciudad y sobre todo las mujeres, va a aquel río Manzanares, al puente Segobiano, y allí gentes del populacho, tanto hombres como mujeres, se lavan entremezclados con poco recato para el servicio del alma. Aquellos otros de [mejor] con-

29. ÖStA. AVA-FA. Hs. 6. vol I, p. 231.

30. VIGARELLO: op, cit. p. 105.

31. CAVALlo, Sandra: op, cit. p. 181.

32. PILS, Susanne Cl: Schreiben über Stadt. Das Wien der Johanna Theresia Harrach, Wien, 2002, p. 204.

33. ÖStA. AVA-FA. Hs. 6. vol I, p. 201.

34. Anónimo español, El Manzanares durante la fiesta de San Juan, siglo XVII, reproducido en: EBBEN, Mauritus: Un holandés en la España de Felipe IV. Diario de viaje de Lodewijck Huygens, Madrid, 2012. 
dición pasan la velada yendo de arriba abajo, así como entrando con las carrozas en el río para gozar de las locuras de estos [primeros] ${ }^{35}$

Con motivo de la Noche de San Juan, Harrach salió al Prado con su carroza la tarde del 23 de junio de 1674; aunque nunca sabremos si llevaba intención de meterse en el río porque una fuerte lluvia le obligó a volver a casa ${ }^{36}$. De cualquier manera, merece la pena resaltar el contraste entre estas abluciones públicas de carácter popular que tanto rubor provocaron a Del Pozzo y los baños privados de Harrach que pertenecen a la idiosincrasia de una aristocracia cortesana con necesidades corporales y espirituales específicas. El análisis de los tiempos elegidos para sus inmersiones o vaporizaciones y las actividades que las rodeaban son claves para comprender el significado cultural que estas prácticas encerraban.

Según indica en su diario, Harrach se bañó en privado un mes después, precisamente un día en el que se dedicó en exclusiva a actividades particulares: visitó al conde de Casa Rubias donde compró libros (unos 500); después volvió a su casa y se dedicó a registrar los ejemplares adquiridos. Tras esta «privada» ocupación, se bañó durante una hora ${ }^{37}$; de lo que se deduce que su baño, siempre de «ein Uhr» de duración, era una práctica de salud encuadrada en una hoja de rutinas situadas al margen de la exposición cortesana; además, su ejercicio iba más allá de la cura de dolencias físicas porque su objetivo último era ayudar al afanado cortesano a soportar las presiones de la vida "pública», cada vez más inaguantables a tenor de los cambios que se estaban produciendo en el seno de una corte más proclive a aceptar en sus selectos círculos a oscuros recién llegados o togados de mediocres orígenes. La alta nobleza hubo de buscar recursos para evitar el verse embargada por la destructora tristeza política. El baño privado iría en consonancia con las prevenciones de la melancolía, la temida compañera de fatigas del cortesano demasiado tenaz, pero también entrañaría deleite y solaz, no expresado por el embajador pero imaginado por el lector contemporáneo.

El perfume gozaba de similares valores terapéuticos a los atribuidos al baño con agua o vapor. Poco se sabe sin embargo del papel que jugarían los aromas en la vida de Harrach, a pesar de que tenía un su poder un recetario manuscrito de perfumes de gran valor que había pertenecido a la Casa de Luis Guillermo de Moncada ${ }^{38}$.

La nariz era arma infalible para detectar las pasiones y reconocer las virtudes, al igual que el ojo se revelaba fundamental para descifrar las bondades del alma que el rostro reflejaba. En contra de las tesis que aseguran que el olfato perdió poder en los

35. Anselmi, Alessandra (ed): El diario de viaje a España del cardenal Francesco Barberini escrito por Cassiano del Pozzo, Madrid, 2004, p. 193.

36. ÖStA. AVA-FA. Hs. 6. vol I, p. 201v.

37. Ibídem.

38. OlivÁn SANTAliestra, Laura y PILO, Rafaella: «Recetario en busca de dueño: perfumería, medicina y confitería en la casa del VII duque de Montalto (1635-1666)», Cuadernos de Historia moderna, en prensa. Es muy posible que el recopilador de las recetas fuera el médico Gabino Farina. Recientemente, Pilo ha sugerido la posibilidad de que se tratara de Luis Mercader, botánico. Por cortesía de Pilo: MAGALOTTI, Luigi: Lettere familiari. 
siglos modernos con respecto a la vista ${ }^{39}$, Jahan asegura que este sentido siguió siendo referente en el cometido de percibir el entorno ${ }^{40}$. Lorenzo Ortiz en su obra Ver, oír, oler, tocar ensalzó al olfato en su oda a la rosa ${ }^{41}$; y en la Iconología de Cesare Ripa, la capacidad olfativa que debe tener el cortesano está representado por un perro que olfatea el terreno, abriendo camino y guiando al resto de los sentidos: la vista y el oído, representados por los ojos y orejas que engalanan la capa de su encapuchado dueño ${ }^{42}$. Dado el importante papel que jugaba el olfato en la Corte, no resulta extraño que los embajadores estuvieran familiarizados con el uso de los perfumes que según se creía modificaban los malos humores ocultando la demasiada cólera, tapando la extremada flema o atenuando las inclinaciones del alma, iracundas en demasía ${ }^{43}$.

Dado el carácter cortesano del perfume, resulta difícil encontrar testimonios personales relativos a su disfrute privado. Aún así, todo un mundo de privacidad secreta e intimista se puede adivinar al leer entre líneas recetarios y libros de secretos. Tímidamente o a veces más explícitamente, al recopilador de recetas se le «escapa» un comentario referente al placer de hacer un perfume lejos de las miradas extrañas o al deleite experimentado al aspirar un aroma en aposentillos recónditos y poco transitados.

El recetario de la casa del VII duque de Montalto presenta una característica especial que lo convierte en inesperada fuente de sensaciones íntimas y experiencias personales relativas al olfato. Lo que hace tan peculiar a este recetario manuscrito que acabó por avatares del destino en manos del conde de $\mathrm{Harrach}^{44}$, son las anotaciones que hizo al margen de cada una de las recetas el recopilador de las mismas, criado y a la vez «artesano» de todos y cada uno de los perfumes que aparecen en el recetario. Según se deduce de sus personales notas, este guardador de memorias, realizó todas las fórmulas con sus propias manos, guiado ora por la misma receta que le había suministrado tal dama o cual guantero, ora por el gusto de su amo o por su personal conocimiento del pantone registrado en la amplia paleta de olores. Sus riquísimas anotaciones sugieren unos usos muy domésticos ${ }^{45}$ de aquellos perfumes, así como una apropiación personal de cada uno de ellos a través un gusto individualizado.

La inclinación por uno $\mathrm{u}$ otro ingrediente personaliza la fragancia y prefigura su utilización privada en lugares domésticos tal y como certifica el fiel criado al registrar recetas con títulos como: «cazoleta de monja» ${ }^{46}$ que según el recopilador proporcionaba un «olorcillo muy lindo para un aposentillo» íntimo y pequeño, o «memoria de

39. SMith, Mark M.: Sensing the past, Los Ángeles, 2007, p. 65.

40. JAHAN, Sébastien: Les Renaissances du corps en occident (1450-1650), París, 2004. p. 217.

41. Ortiz, Lorenzo: Ver, Oír, Oler, Gustar, Tocar, Lyon, 1686, p. 127. BouZA, Fernando: op. cit. p. 200.

42. NAVARRo Bonilla, Diego: Los archivos del espionaje. Salamanca, 2004. pp. 31-32.

43. JAHAN, Sébastien: op, cit. p. 215.

44. ÖStA. AVA-FA. Harrach. Hs. 30.

45. Sobre el uso del perfume en la casa: CAVALLO, Sandra: op. cit. pp. 174-187.

46. ÖStA. AVA-FA. Harrach. Hs 30. p. 10v. 
polvos para perfumar la ropa de cama del invierno ${ }^{47}$, que denota que no hay mejor lugar ni más recóndito para disfrutar de un perfume que el lecho, donde las sábanas impregnadas velan el sueño. La cotidianidad de estos perfumes queda igualmente certificada en la multitud de objetos que iban conquistando los espacios domésticos ${ }^{48}$ $\mathrm{y}$ que en el recetario aparecen por doquier como las porcelanas ${ }^{49}$, las «caxoletas o enjuncieras $»^{50}$. Tampoco ocultan su utilidad doméstica las aguas para «regar en invierno los aposentos» o «rociar ropas de mesa ${ }^{51}$. Junto a los cotidianos continentes, se suceden las expresiones relativas al gusto de Montalto: «mi amo quería que las aguas fuesen fuertes», «mi amo gustava desta agua sin ambar y almizcle porque en los lienzos saliese mas el olor de las flores» $\mathrm{o}$ «mi amo gustava de aquella frescura del vinagre y no le echava aguas de olor fuerte sino rosada de murta».

Merece la pena detenerse en la «Memoria de cazuela de naranjas» pues junto a su sencilla fórmula, el criado suscribe: «Es cosa muy ordinaria pero mi amo como últimamente no podía sufrir el ambar gustava mucho de estas cazoletas». Al hacedor de perfumes no le convencía aquella receta pero aquello no era excusa para no satisfacer a su amo, que en los últimos tiempos no podía soportar el olor del ámbar, por cierto, muy vinculado por su fuerza y consistencia a la representación cortesana. ¿Acaso Montalto sufría tal melancolía y desazón que sólo podía aguantar el agua de azahar, sana fragancia tan extraña al mundo palaciego? Jehan Lhermite alabó el olor de los naranjos de Valencia testimoniando lo siguiente: «Y no es posible describir con palabras el buen olor que despiden estos árboles cuando florecen, pues creo que no hay en el mundo fragancia por artificial que sea que pueda igualarse a esta ${ }^{52}$. Los naranjos florecían en arcadias, lejos de los enrarecidos ambientes cortesanos.

No sabemos a ciencia cierta a qué momento de la vida se refiere el criado de Montalto cuando afirma que «últimamente» su amo no podía soportar el ámbar, aunque podríamos aventurar una posible fecha en torno a la década de los cincuenta, momento en el que el sufrido duque estaba luchando por encontrar un hueco en la corte. Montalto fue desgranando la desazón que le embargaba en aquellos aciagos tiempos por medio de correspondencias con el marqués de Castelrodrigo, otro sufridor, aunque de podagras, que pasaba sus días refugiado en su bella villa de La Florida. El duque no dejaba de lamentar su desgracia cuando, perdido por las calles de Madrid, pensaba en el zaratán que atormentaba a su esposa en tierras valencianas y en el poco provecho político que sacaba a sus visitas a la Corte:

47. Ibidem, p. $42 \mathrm{v}$.

48. VigARELLO, Georges: Lo sano y lo malsano. Madrid, 2006, p. 173.

49. ÖStA. AVA-FA. Harrach. Hs. 30. p. 10.

50. Ibidem, p. 32.

51. Ibidem. p. 5.

52. Lhermite, Jehan: Pasatiempos de Jehan Lhermite. Editado por Jesús Sáez de Miera. Madrid, 2011, p. 470 . 
«...quatro meses ha que estoy en la corte. Italia y el mundo discurren en ver que se esta muriendo la Duquesa de Montalto arrojada en las costas de España y sola, quando yo me hallo sin conveniencia sin decoro y sin voluntad, ocioso en las calles de Madrid» ${ }^{53}$.

El empeño de Montalto tuvo su recompensa y aunque tuvo que pasar por la muerte de su mujer, consiguió sus objetivos al ser nombrado mayordomo mayor de doña Mariana de Austria ${ }^{54}$. Aunque sus triunfos durarían poco. Tras su participación en la conspiración contra Nithard $^{55}$, probaría las hieles del desengaño. Su tristeza le habría llevado más de una vez a encerrarse en perfumados aposentillos o a soportar los tórridos veranos de la Villa con vinagres de juncia, de gran poder desinfectante pero también dispensadores de una agradable y placentera sensación de frescor ${ }^{56}$. La muerte le sorprendió en mayo de 1672.

El 11 de mayo de 1674, el conde de Harrach pasó por su almoneda, allí, según relata en su diario, sólo compró algunos libros ${ }^{57}$. Quién sabe si entre esos pocos ejemplares estaba este manuscrito encuadernado tamaño cuartilla, contenedor de bellas recetas de perfumes pero sobre todo de hermosos testimonios sobre el gusto y el placer privado.

\subsection{En camas, sobre escritorios: lecturas en silencio y escrituras privadas}

Una de las ocupaciones habituales del conde de Harrach era leer despachos, cartas o demás escritos que correspondían al oficio de su embajada. En su diario, raras son las veces en las que el embajador deja constancia de un rato de lectura para entretenerse, lo cual no quiere decir que este tipo de práctica no fuera más frecuente de lo que parece indicar su registro personal.

Se pueden rastrear estos momentos de esparcimiento entre páginas. En una ocasión dedicó el día a leer porque el tiempo estaba muy ventoso y llovía: «Weillen das wetter windig undt geregnet, bin ich nit aussgangen, sondern zu hauss mit lesen die zeit zuegebracht $»^{58}$. En otro momento, se entretuvo leyendo para luego ir a San Bernardo en carroza y volver andando, una sana práctica que permitía la sutil y saludable evacuación de los flujos invisibles ${ }^{59}$. Aquellas lecturas parecen ligadas de una u otra manera con las prácticas de la salud: el viento era considerado muy peligroso para la integridad de los cuerpos y las caminatas suaves permitían liberar los malos humores ${ }^{60}$. En otros testimonios se observa con más claridad esta relación cuando, por ejemplo, después

53. AHN. Estado. Libro 104. 1659.

54. PILO, Rafaella: Luigi Guglielmo Moncada e il governo della Sicilia (1635-1639), Roma, 2008, p. 205

55. PILO, Rafaella: La correspondencia del cardenal Moncada y la conjura contra Nithard, en La Dinastía de los Austria. J. MARTínez Millán y M. P. MARÇAl LourenÇO (coords.), Madrid, 2011, II, pp. 10751088.

56. VigARELLO, Georges: Le prope..., p. 100.

57. MENCIK, Ferdinando: Tagebuch über den Aufenthalt in Spanien in den Jahren 1673-1674, Wien, 1913, p. 90.

58. ÖStA. AVA-FA. Harrach, Hs 6. vol I, p. 247.

59. Ibidem, pp. 243v-244.

60. Vigarello, Georges: Lo sano .... p. 127. 
de las purgas que su doctor Billiote le practicaba y que le obligaban a permanecer en la cama, decía «entretenerse» leyendo un libro $^{61}$, situación que se repite en varias ocasiones $^{62}$.

Como si de una medicina se tratara, la lectura permitía al conde cultivar y sanar un espíritu algo apesadumbrado por el tratamiento sufrido. Imaginamos que leería el libro en silencio, pues la convalecencia no le permitiría gastar energías activando la voz. El lecho donde Harrach estaba postrado adquiría en aquel momento un carácter íntimo donde el libro, en silencio leído y a modo de contribuyente a la recuperación, encaja a la perfección. Por desgracia, el embajador no cita el título de la obra que le ayudaba a pasar con mayor alivio esos ratos amargos, aunque conociendo al conde, apasionado del teatro y asiduo espectador en los corrales de comedias, no hay razón para no suponer que alguno de esos libros que lograban atenuar sus dolores post-sangría fuera una obra de Calderón de la Barca. No dispongo de un inventario que especifique todos y cada uno de los títulos de su biblioteca pero, sin duda alguna, en ella abundaba el teatro. Lo demuestran los dieciséis volúmenes dedicados al teatro y con más de cien piezas, treinta de las cuales eran de Calderón de la Barca, que los condes de Harrach legaron a su hija ${ }^{63}$.

La que sí era una gran lectora de comedias españolas era su mujer; afición que a veces practicaba en silencio: «naher angefangen ein spanische comedi zu lesen 2 josnados» ${ }^{64}$ y otras en voz alta delante de su hermana Porcia ${ }^{65}$, la cual escucharía con emoción contenida. Cabe suponer que como se solía hacer con La Celestina ${ }^{66}$, la lectura de la condesa de Harrach fuera teatralizada: cambiaría la voz de registro al entonar los diálogos de uno y otro personaje y gesticularía, aunque fuera someramente, alguna de las escenas. Era esta una práctica, la lectura en voz alta, muy común entre mujeres ${ }^{67}$. De sus Tagzettel se deduce igualmente que leía con su hermana Las cosas de Rübenzahl ${ }^{68}$; y en silencio la vida de Santo Tomás de Aquino: «Heidt bin ich umb 6 mundter Worden und hab ihn leben daz heilgen Tomäss von Aquin gelesen bis $7 »^{69}$, lectura a la que aquel día dedicó una hora, el mismo tiempo que su marido empleaba para tomar su baño. Quizás la vida de Santo Tomás le sentaba tan bien a su alma como el vapor y agua caliente al cuerpo de su esposo.

Con respecto a la escritura, los dos miembros del matrimonio se entregaron con similar énfasis a la escritura biográfica, alentada por un cúmulo de inquietudes entre

61. ÖStA. AVA-FA. Harrach, Hs 6. vol I p. 198.

62. Ibidem, p. 242 y p. $246 \mathrm{v}$.

63. REICHENBERGER, Arnold: «The counts Harrach- and the Spanish theater», en Homenaje a Rodriguez Moñino. Madrid, 1966, pp. 97-103.

64. ÖStA. AVA-FA. Harrach. Kt. 350. PILS, Susanne Cl.: op, cit. pp. 18-19.

65. Ibidem.

66. CHARTIER, Roger: «Las prácticas de lo escrito» en DUBY, Georges y ARIÈs, Philippe, op.cit., p. 147.

67. BouZA, Fernando: op, cit. p. 48.

68. PILS, Susanne, Cl: op, cit. p. 18.

69. ÖstA-AVA, FA Harrach Kt. 350 TZ 6: PILS, Susanne: op, cit. p. 19. 
las que se pueden contar el deseo de preservar la memoria, el mero solaz o el desahogo $^{70}$. Harrach escribió un diario durante su embajada mientras que Johanna Teresia se decantó por las Tagzettel. Las llamadas Tagzettel son verdaderas pláticas entre los dos cónyuges, una prolongación de sus conversaciones cotidianas que la condesa decidió iniciar para cubrir una necesidad sentimental provocada por la ausencia del esposo entre el 11 de julio de 1665 y el 23 de diciembre de 1665, meses durante los cuales el conde de Harrach tuvo que cumplir con una embajada extraordinaria en Madrid. La condesa inició una segunda fase de Tagzettel cuando se vio obligada a salir de Madrid con sus hijos a principios de septiembre de 1676 y su marido tuvo que quedarse en la Corte cumpliendo su embajada ordinaria. Esta segunda tanda de notas-diario duró casi un año: del 27 de noviembre de 1676 al 5 de noviembre de $1677^{71}$.

Resulta interesante observar cómo la condesa escogió la lengua dialectal y el registro directo que le permitía escribir: «alss wie ich redt» ${ }^{72}$. «Escribo como hablo», suscribía orgullosa y agradecía que su marido le contestara utilizando ese mismo tono conversacional ${ }^{73}$. Johanna también eligió un peculiar lugar para reproducir en el papel pláticas cotidianas con su marido: la cama ${ }^{74}$. Allí se sentía libre para expresar sus confidencias referentes a los celos, la sexualidad, el amor, la crianza de los hijos, la cocina, la salud o la gestión doméstica, temas que pueblan las tagzettel de la primera separación entre los esposos. En la segunda fase, las intrigas y ciertas cuestiones políticas se cuelan en la cotidianidad conversacional del matrimonio. La escritura de estas dos fases de Tagzettel con temáticas diferentes podría interpretarse como un escaso interés de Johanna por los temas políticos, nada más lejos de la realidad: que Johanna no escribiera un diario como el de su marido o que sus primeras Tagzettel versaran sobre domesticidades no implica que no tuviera una intensa agenda político-cortesana, lo que ocurría es que su influencia se vehiculaba más a través de la oralidad que de la escritura diaria.

Cartas privadas, tagzettel, despachos oficiales, diarios, recetarios, libros de secretos y piezas teatrales...debían preservarse, como preciados tesoros que eran, en continentes y lugares adecuados a su secreta condición. Los condes de Harrach se esmeraron en cuidar su memoria. La condesa de Harrach sentía una especial predilección por los escritorios indianos: se sabe que mostró una gran preocupación cuando al llegar a Viena en 1676, se percató de que aún no habían arribado sus bellos escritorios. Al leer su testamento se constata que aquellos muebles llegaron a su destino pues pudo legar

70. MARTínEZ, Santiago: «Memoria aristocrática y cultura letrada... p. 96.

71. PILS, Susanne Cl.: op, cit, p. 23.

72. Ibídem.

73. Ibidem.

74. Ibidem, p. 162. 
a cada una de sus hijas un escritorio de la India ${ }^{75}$ y otro, más pequeño (el que estaba en su cámara de dormir) a su nuera Cecilia ${ }^{76}$.

Sólo el tiempo sabe dónde acabaron esos escritorios, lo que sí ha llegado hasta nuestros días son las tagzettel de la condesa y el diario del conde Harrach. Estas escrituras autobiográficas, rompiendo todos los esquemas, han resistido los infortunios amenazantes de la frágil memoria nobiliaria. La última llave que ha permitido abrir el simbólico escritorio indiano donde estos manuscritos reposaban ha sido la generosidad de los descendientes. Su disposición ha permitido a los investigadores acceder al contenido de aquellas escrituras privadas, celosamente guardadas por sus dueños en bellos muebles de la India. Sin duda, en la época, la cámara y el tesoro se confundían...

\subsection{Chocolate, limonada y conversación «privada»}

El 16 de mayo de 1674, el conde de Harrach fue a visitar la casa y huerta del Almirante, don Juan Gaspar Alonso Enríquez de Cabrera, IV duque de Medina de Rioseco. Harrach no podía desaprovechar la oportunidad que se le brindaba de conocer una de las colecciones de pintura más importantes de la Villa y Corte. Después del recorrido por el palacio, el conde y su anfitrión salieron a la huerta y en aquel idílico lugar, Harrach fue obsequiado con una limonada fresca, nieve azucarada y chocolate caliente acompañado de $\langle\text { Biscoten }\rangle^{77}$. Imaginamos que durante sus paseos por la maravillosa Huerta, Harrach y el Almirante conversarían, es decir, según el Tesoro de la lengua castellana, «tratar[ían] urbanamente, y comunicar[ían] con otros» o mantendrían una, como suscribía Harrach, «conversation» que era «la comunicación y plática entre amigos $\gg^{78}$. Ambos comunicantes serían conversables, es decir apacibles, tratables. La conversación entre los dos magnates versaría sobre temas no políticos: arte, literatura o teatro; discurriría calmada, sosegada y conforme a lo que debía ser: un hábito nobiliario pero, ante todo, un descanso del alma o desahogo privado practicado entre «amigos». En definitiva, un concepto de conversación expuesto por Gracián en su obra: $E l$ Arte de la prudencia:

«Tener el arte de conversar, en que se hace muestra de ser persona. En ningún ejercicio humano se requiere más la atención, por ser el más ordinario del vivir. Aquí es perderse o el ganarse [...] La discreción en el hablar importa más que elocuencia» ${ }^{79}$.

El conde de Harrach distinguía muy bien en su diario entre «reden» que significaba «hablar», y «conversar», pues para indicar que conversaba utilizaba la palabra española conversación. Esta diferenciación no era baladí, al contrario, estaba muy pensada y reflexionada. En ocasiones, Harrach sólo indica que mantuvo una conversation $^{80}$,

\footnotetext{
75. Ibidem. p. 109.

76. ÖStA. AVA-FA. Harrach. Kt. 205.

77. MENCIK, Ferdinando: op, cit, p. 91.

78. COVARRUBIAS, Sebastián: op. cit. p. 236.

79. GRACIÁN, Baltasar (1601-1658): El arte de la prudencia, Mallorca, 2000, p. 67.

80. ÖStA. AVA-FA. Harrach. Hs. 6. vol. II. p. 29 v,
} 
otras, especifica el lugar y las identidades de los interlocutores: en su casa o en «la aldea», en los jardines de Liche ${ }^{81}$ o en la huerta del Almirante ${ }^{82}$ al que Harrach consideraba su «amigo» ${ }^{83}$, o en la casa de don Luis de Cárdenas adornada con cuadros de El Bosco y con un jardín lleno de flores. El cuarto bajo del conde de Baños o la casa de don Pedro de Aragón ${ }^{84}$ fueron otros escenarios propicios para las conversaciones. La Florida, la flamante villa urbana del marqués de Castelrodrigo estaba igualmente entre los sitios favorables a la conversation porque aunque el marqués estaba aquejado de la podagra y pasaba los días postrado en la cama, su mal no era tan grande como para que no le alegrara la visita de un amigo ${ }^{85}$.

Pero quizás el sitio más inaudito para entablar conversation fuera la habitación de la abadesa del monasterio de Santo Domingo El Real y no sólo por la estrechez del lugar, tan alejado de los esparcimientos posibles en huertas y jardines, sino por la originalidad de algunos de los contertulios entre los que cabe destacar María Mancini, la condestablesa Colonna, antigua amante de Luis XIV, sobrina de Mazarino y dama huida de los brazos de su marido en una oscura noche romana y vestida de hombre. La condestablesa había llegado a Madrid con la esperanza de encontrar un buen refugio lejos de las persecuciones de su esposo y las presiones de Luis XIV. Pero hasta en la Babilonia de Madrid, la sobrina de Mazarino no había podido sustraerse a los tentáculos de ambos patriarcas. A su llegada a la Villa, el Almirante la había acogido en su dulce huerta ${ }^{86}$; allí, María Mancini había pululado por pasillos y parterres como una exótica pieza de arte más de las que don Juan Gaspar poseía. Mala esposa, trasgresora de las apariencias, bella ex-amante de Luis de Francia, la condestablesa Colonna cumplía todos los requisitos de dama merecedora de la condena del exilio, de la pena de aldea. De la apacible huerta del paseo de Recoletos fue conducida al madrileño monasterio de los Ángeles y de allí al de Santo Domingo el Real, donde Victoria de Porcia fue la única cara amable de aquel encierro dictaminado por el condestable ${ }^{87}$. Victoria de Porcia, hermana del conde de Mortara era además de abadesa, mujer versada que conocía la lengua italiana ${ }^{88}$ y gustaba de invitar a su convento a embajadores y nobles cultivados.

El 4 de octubre de 1674, Harrach, junto al nuncio y al embajador de Venecia, visitó el monasterio de Santo Domingo por vez primera; allí pudo comprobar cómo la condestablesa vivía en una casa al lado del claustro y cómo discurría su retiro con ciertas libertades amablemente permitidas por su amiga la abadesa. El Almirante acu-

\footnotetext{
81. Ibídem, vol. I, p. 213v.
}

82. FRUTOS, Leticia: «Arte, política y literatura entre Lisboa y Madrid: el Marqués del Carpio, Riberio de Barros y la Corte madrileña», Actas del congreso Portugal, a Europa e Oriente, en prensa.

83. Ibídem, vol. I, p. 248.

84. Ibídem, vol. I, pp. 238-240v.

85. Ibídem, p. 216.

86. MALLET-JoRIs, Françoise: Marie Mancini, p. 257.

87. ÖStA. AVA-FA. Harrach. Hs. 6, vol I, p. 243.

88. MANCINI, Hortense et Marie: Mémoires de Marie Mancini, Mesnil-sur-l’Estrée, 2003. p. 189. 
dió después, cuando el grupo entró en la habitación de sor Victoria, donde tomaron chocolate y limonada para luego entrar «ein wenig in der conversation». La plática no debió durar mucho pues Harrach suscribió que, como comenzaba a hacerse de noche, cada uno se había ido andando a su casa ${ }^{89}$.

Mucho más se prologó la conversation del 27 de diciembre; esa fría tarde de invierno, Harrach visitó a doña Victoria y a la condestablesa en uno de los cuartos del monasterio. Cuando el conde llegó, las damas estaban en compañía de un caballero que pronto se marchó y en su lugar apareció el embajador de Venecia con el que estuvieron más de tres horas conversando ${ }^{90}$. Con la presencia de Harrach, buen conocedor de pintura; María Mancini, gran aficionada al arte, y del embajador veneciano, importante contacto en temas de mecenazgo artístico, no es difícil adivinar sobre qué versaría la conversation. Cuadros, arte, literatura y demás solaces del espíritu entretendrían a los dos diplomáticos y a aquellas dos mujeres cobijadas en un hortus conclusus. Pocos días antes Harrach había vuelto a la huerta del Almirante para admirar sus pinturas. Antes de comenzar el recorrido por cada una de las obras, don Juan Gaspar le ofreció, como la vez primera, chocolate y biscotes, no así limonada, bebida que elegantemente sustituyó por agua fresca ${ }^{91}$. Tanto el chocolate como la limonada curaban melancolías y favorecían la conversación de íntimos amigos. Harrach y el Almirante lo fueron y, con su amistad, rompieron la tónica política de las relaciones sociales tradicionalmente establecidas en los contextos cortesanos. Nuevas formas de sociabilidad se empezaban a asentar en los aledaños de la Corte barroca.

\section{CONCLUSIONES: DEL RECURSO AL PLACER ${ }^{92}$}

La condesa de Harrach ahogaba soledades «hablando» en la cama a los papeles a su marido destinados; María Mancini, encerrada en un convento, se consolaba de su desgracia conversando en italiano con una letrada abadesa; el Almirante paseaba su melancolía por su deliciosa Huerta, degustando fría limonada con ardiente chocolate; Castel Rodrigo templaba los dolores causados por la podagra con la visita de algún íntimo amigo; el duque de Montalto se rodeaba de juncias y naranjas para soportar las limpias estocadas cortesanas y el conde de Harrach procuraba no caer en melancolías tomando un largo baño o leyendo un libro entre sábanas tras las obligadas purgas dictadas por su médico. La nobleza melancólica, desazonada, exiliada y recluida se refugiaba en burbujas culturales para recuperar fuerzas o simplemente rumiar su desgracia.

Como afirma Bouza, detrás de este escapismo involuntario perpetrado por una quejumbrosa alta nobleza se encuentran las profundas transformaciones sociales y políticas ${ }^{93}$ de finales del siglo XVII y principalmente las presiones de grupos socia-

89. ÖStA. AVA-FA Harrach, Hs. 6. vol I, p. 243v.

90. Ibidem, vol I, pp. 287-287v.

91. Ibídem, vol I, p. 280.

92. VigareLlo, Georges: Lo sano y lo malsano, pp. 172-173.

93. BouZA, Fernando: op cit. p. 214. 
les ajenos a las altas esferas que afectaron profundamente al modus operandi nobiliario. Estos cortesanos relegados de la esfera política descubrieron en los espacios y tiempos a los que les había conducido su pesadumbre, el divertimiento, el gusto y el placer, eso sí, vividos con virtud eutrapélica. Las fatigas de la agitada función palaciega en tiempos turbulentos abonaría el terreno para el deleite exclusivamente privado proporcionado por las sofisticadas técnicas del cuidado del cuerpo y tratamiento del alma, porque volcar los sentimientos en el papel o refugiarse en la pluma para vivir con menores desvelos fueron prácticas preservadoras de sanos espíritus, tan necesarias como placenteras ${ }^{94}$.

Hombres y mujeres del siglo XVII, hijos de la corte barroca pertenecientes a familias de alto abolengo, contribuyeron a la construcción de sociabilidades y privacidades modernas. Estas vidas privadas de favores fueron la antesala a unas verdaderas vidas «privadas». Esta tesis viene a erosionar las barreras seculares que separan de manera tajante la sociabilidad de los siglos XVII y XVIII, pues esa cultura de la conversación mundana y esas prácticas de privacidad reivindicadas fundamentalmente desde sectores dieciochistas se pueden encontrar en un espacio, la Corte, y en un grupo social, la nobleza, que tradicionalmente se han situado al margen del nacimiento de lo privado en las sociedades occidentales. Según los discursos tradicionales en torno a la construcción de la privacidad fueron los tramos medios de la sociedad ${ }^{95}$, la burguesía y quizás la baja nobleza, los que abanderaron la construcción de los primeros espacios privados o domésticos, renegando de la sociabilidad y cultura cortesanas así como de sus irrisorios protagonistas. Sin embargo, el investigador que se acerca a las fuentes del Siglo de Oro desde la atalaya de la representación política, se ve asaltado por los espacios y tiempos privados de una nobleza cortesana partícipe y protagonista de las grandes transformaciones socio-culturales que triunfarían en el siglo XVIII.

\section{COLOFÓN: UN GATO Y UN JARDÍN}

La condesa de Harrach salió de Madrid el 3 de septiembre de 1676. Junto a ella viajaban sus hijos, su servidumbre, un perro y un gato ${ }^{96}$; llevar este último animal doméstico es una prueba de la avanzada sensibilidad de Johanna Theresia, ya que la nobleza del siglo XVII era más proclive a simpatizar con los canes que con los diabólicos felinos ${ }^{97}$.

El conde de Harrach no pudo acompañar a su esposa, sus obligaciones de embajada lo retuvieron en una corte que estaba al borde de la guerra civil. Harrach comenzó

94. MARTíNEZ, Santiago: op, cit. p. 60.

95. ÀrIES, Philippe, op, cit, p. 15.

96. PILs, Susanne Cl.: op, cit. p. 89.

97. El gato empezó a ser animal de compañía de los románticos en el XIX, tal y como me comentó una vez Carlos Gómez-Centurión. Sobre los animales en la corte véase su magnífico estudio que nos ha dejado a modo de testamento historiográfico: GóMEZ-CENTURIón, Carlos: Alhajas para soberanos. Los animales reales en el siglo XVIII, Valladolid, 2011. 
entonces su etapa más dura en Madrid. A finales de 1676 don Juan dio un golpe de estado que acabó con la regencia. En enero de 1677 el conde asistió perplejo al exilio de la reina madre. Vanos fueron sus esfuerzos por salvar a doña Mariana y rehabilitarla políticamente. Durante una acalorada discusión con el cardenal de Aragón, que pretendía enviar a la reina al exilio toledano, el impotente Harrach llegó a contestar: «si no he de [hazer] nada, no tiene que tener Embajador su Magestad Cesarea, y que [qual] quier palo o legno puede representar mi carácter ${ }^{98}$. Al pronunciar estas palabras, definió su nueva situación: al borde del abismo político. Este nuevo estado ¿acaso le obligó a cruzar la línea entre la corte y la aldea? ¿Le condujo a cultivar con más ahínco la conversación de jardín, contestar con mayor frecuencia las tagzettel de su esposa, entretenerse con un libro o tomar un baño?

Espoleado por la desgracia política, Harrach volvió a Viena en 1677. Melancólico pero acaso con un nuevo espíritu de agudeza y discreción de gran valor social, el conde se presentó en la corte Imperial con un amplio y renovado bagaje cultural ${ }^{99}$. Leopoldo supo valorar a su viejo diplomático y lo convirtió en Oberststallmeister, una condición «pública» que no podría borrar las prácticas de consuelo aprendidas en Madrid. Aunque no privado de cargo político, en Viena, los apartamentos privados del conde daban a un amplio jardín...

98. ÖStA, AVA-FA. Harrach Hs. 6, vol II, p. 225v.

99. LINDORFER, Bianca: «Las redes familiares de la aristocracia austriaca y los procesos de transferencia cultural», YUN CASALILLA, Bartolomé (coord.): Élites sociales en la articulación de la monarquía hispánica, Madrid, 2009, pp. 261-288. 